\title{
The Impact of Foreign Trade on China's Industrial Transformation and Upgrading
}

\author{
Jun Chen ${ }^{1, *}$ \\ ${ }^{1}$ Shandong Vocational College of Science and Technology, Weifang, China
}

\begin{abstract}
In the context of the continuous opening up of China's foreign economic development, the coordinated development of foreign trade and industrial transformation and upgrading has always been a hot issue in industrial economics and international trade research. Through empirical analysis to study the impact of foreign trade on industrial transformation and upgrading, this paper finds that there is a long-term dynamic synergy relationship between foreign trade and industrial transformation and upgrading. At the same time, this article also finds that the export value of goods trade and the import value of service trade have a significant impact on industrial transformation and upgrading, while the import value of goods trade and the export value of service trade have no significant impact on the industrial transformation and upgrading. Finally, this article puts forward policy recommendations on the promotion of industrial transformation and upgrading by foreign trade on this basis, so as to provide references for industrial policy makers.
\end{abstract}

\section{Introduction}

With the continuous progress of scientific and technological innovation, economic globalization continues to develop in depth. The influence of foreign trade structure on industrial transformation and upgrading is increasing. The structure of foreign trade is also playing an increasingly important role in the global value chain. At present, China is in a critical period of transformation and upgrading of its economic structure and a comprehensive increase in the level of opening up. Studying the impact of foreign trade on China's industrial transformation and upgrading, and discovering problems, finding the reasons, and proposing countermeasures can promote the development of foreign trade, and it is also more conducive to industrial transformation and upgrading. Studying the impact of foreign trade on industrial transformation and upgrading is also conducive to perfecting the development mode of the national economy, thereby promoting the highstandard and high-quality development of the Chinese economy.

\section{Literature review}

Experts and scholars at home and abroad mainly conduct research on technology spillover, capital accumulation, factor flow and international industrial transfer. Many scholars have analyzed the impact of foreign trade on industrial transformation and upgrading from the perspectives of theory and practice, and have drawn a large number of unique conclusions [1]. In terms of theory, since there has been no substantial breakthrough in the connection between international trade and industrial transformation and upgrading in recent years, early Ricardo's theory of comparative advantage, Vernon's product life cycle theory, and HeckscherOlin's factor endowment theory, Akamatsuyao's geeseshaped development model theory and strategic trade policy theory are still the main theoretical basis for the impact of foreign trade on industrial transformation and upgrading [2]. In terms of empirical research, in recent years, it has mainly focused on the impact of trade structure optimization on industrial structure. For example, Fan Aijun of Shandong University studied the impact of general trade and processing trade on the upgrading of China's industrial structure. Jiang Li from Dongbei University of Finance and Economics conducted an empirical study on the impact of trade in goods and services on the industrial structure. Sun Xiaohua of Dalian University of Technology studied the driving effect of two major categories of trade products, industrial manufactured products and primary products, on the upgrading of industrial structure. Wen Kun of Nanchang University studied the relationship between the adjustment of foreign trade structure and the upgrading of industrial structure in Guangdong Province. Chen Jinling from Jincheng Vocational and Technical College used the SVAR model to conduct an empirical study on the relationship between the changes in China's export commodity structure, the optimization and upgrading of the industrial structure, and the dynamic impact of economic growth [3]. Tang Huiliang from Yichun University studied the impact of optimization of foreign trade structure on industrial transformation and upgrading. Ma Fei of Guangdong University of Finance

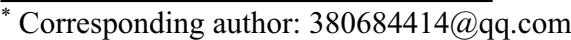


studied the promotion path of China's service trade export to the adjustment of industrial structure. Sun Li of Liaoning University studied the impact of changes in the trade structure between China and Japan on the transformation and upgrading of China's industrial structure [5]. Bu Wei from Beijing Jiaotong University studied the impact of China's foreign trade commodity structure on the upgrading of industrial structure [6].

Judging from the domestic research literature, most experts and scholars mainly use econometric models to study the impact of commodity trade on the optimization and upgrading of industrial structure. However, from the perspective of trade in goods and services, there are few empirical analyses on the impact of foreign trade on industrial transformation and upgrading.

\section{Quantitative analyses of the level of industrial transformation and upgrading}

\subsection{Selection of indicators for measuring the level of industrial transformation and upgrading}

Industrial transformation and upgrading refers to the process of industrial structure transformation and industrial quality improvement. At present, domestic experts and scholars have many methods to measure the level of industrial transformation and upgrading, mainly including the proportion of the three major industries' added value in GDP, the mole value measurement method, and the Lilie index method. These methods have analyzed and investigated the direction and speed of industrial transformation and upgrading, but they have not fully reflected the transformation quality of industrial structure in industrial transformation and upgrading. In order to achieve this goal, we constructed a measure that reflects the quality of the conversion. First, the proportion of the three major industries in GDP is used as a component of the space vector, so that a set of threedimensional vectors $X$ can be constructed, and then the industrial upgrade quality vector $\mathrm{H}$ and the three components $\mathrm{X}_{1}, \mathrm{X}_{2}$, and $\mathrm{X}_{3}$ of the vector $\mathrm{X}$ can be calculated in turn. The included angles are $\alpha_{1}, \alpha_{2}$ and $\alpha_{3}$, and finally the included angles are combined into an index $W$ to measure the quality of industrial transformation and upgrading. The calculation formula is shown below.

$$
\begin{aligned}
& \theta_{\mathrm{j}}=\arccos \left[\frac{\sum_{\mathrm{i}=1}^{3}\left(\mathrm{x}_{\mathrm{ij}}, \mathrm{x}_{\mathrm{i}, 0}\right)}{\sum_{\mathrm{i}=1}^{3}\left(\mathrm{x}_{\mathrm{i}, \mathrm{j}}^{2}\right)^{1 / 2} \sum_{\mathrm{i}=1}^{3}\left(\mathrm{x}_{\mathrm{i}, 0}^{2}\right)^{1 / 2}}\right] \\
& \mathrm{W}=\sum_{\mathrm{K}=1}^{3} \sum_{\mathrm{j}=1}^{3} \theta_{\mathrm{j}}=3 * \theta_{1}+2 * \theta_{2}+\theta_{3}
\end{aligned}
$$

When the calculated $\mathrm{W}$ value is larger, it indicates that the quality of industrial transformation and upgrading is higher. Conversely, the smaller the $\mathrm{W}$ value, the lower the quality of industrial transformation and upgrading. We call the $\mathrm{W}$ value the industrial transformation and upgrading coefficient.

\subsection{Actual measurement results of $W$ value}

According to the above calculation formula, using China's 2019 Statistical Yearbook and the 2019 National Economic and Social Development Statistical Bulletin as samples, the measurement results of China's W value in the past ten years are shown in Table 1 .

Table 1. China's industrial transformation and upgrading $\mathrm{W}$ value from 2009 to 2018

\begin{tabular}{|l|l|l|l|l|l|l|l|l|l|l|}
\hline Year & 2009 & 2010 & 2011 & 2012 & 2013 & 2014 & 2015 & 2016 & 2017 & 2018 \\
\hline
\end{tabular}

\begin{tabular}{|l|l|l|l|l|l|l|l|l|l|l|}
\hline W Value & 6.61 & 6.62 & 6.64 & 6.65 & 6.65 & 6.68 & 6.69 & 6.75 & 6.89 & 6.92 \\
\hline
\end{tabular}

From the data in Table 1, it can be seen that the quality of China's industrial transformation and upgrading has been significantly improved year by year in the past ten years. This shows that "accelerating the transformation of economic development mode and promoting the optimization and upgrading of industrial structure" proposed in the report of the 17th National Congress of the Communist Party of China, "accelerating the transformation and upgrading of traditional industries" proposed in the report of the 18th National Congress of the Communist Party of China, and "supporting Requirements such as optimization and upgrading of traditional industries and accelerating the development of modern service industries have been well implemented. China's economic development has entered a stage of deep integration of technological innovation and industrial economy. At the same time, technological innovation has also brought about industrial transformation and upgrading.

\section{Empirical analyses}

\subsection{Selection of variables}

In order to facilitate the analysis of the different effects of trade in goods and trade in services on industrial transformation and upgrading, this paper selects the industrial transformation and upgrading coefficient $\mathrm{W}$ as the explained variable TST. The export value of goods trade CEX, the import value of goods trade CIM, the export value of service trade SEX, and the import value of service trade SIM are used as explanatory variables. This article uses the 2009-2018 statistical data from the National Bureau of Statistics, the Ministry of Commerce and the WTO as samples. Taking into account the influence of price level factors, this article processes the original data. This article uses 2009 as the base period and converts the data of various economic variables into actual amounts calculated at constant prices in the base period. Because there may be heteroscedasticity when using time series data as a sample, in order to eliminate the negative impact of heteroscedasticity, this paper takes natural logarithmic transformation processing on each economic variable. 


\subsection{Empirical analysis}

\subsubsection{Stationarity test}

In order to avoid the occurrence of the "false regression" problem, this article uses the extended ADF (Augment Dickey-Fuller Test) unit root test method in econometrics to test the stationarity of each variable in turn. The test principle is that if the absolute value of the t-statistic of the ADF test is greater than the absolute value of the critical value under a given significance level (such as $1 \%, 5 \%$, or $10 \%$ ), it means that the economic variable sequence is stationary. On the contrary, it shows that economic variables are not stable. This paper uses the special software Eviews9.0 for econometrics to perform ADF unit root test results on the above five economic variables, as shown in Table 2. It can be seen from Table 2 that the five economic variable series are all non-stationary, but their first-order difference series are all stable at the $1 \%$ significance level, that is, the preconditions for the cointegration test are met.

Table 2. Unit root test results of stationarity of each variable

\begin{tabular}{|c|c|c|c|c|c|c|}
\hline Variable & Inspection Form & ADF Value & $1 \%$ & $5 \%$ & $10 \%$ & Conclusion \\
\hline Ln(TST) & $(C, T, 1)$ & $-\mathbf{0 . 8 5 3}$ & $-\mathbf{2 . 9 8 2}$ & $-\mathbf{2 . 5 5 3}$ & $-\mathbf{2 . 2 8 6}$ & unstable \\
\hline DLn(TST) & $(C, 0,0)$ & -4.783 & -3.726 & -3.209 & -2.977 & stable \\
\hline Ln(CEX) & $(C, T, 1)$ & -2.783 & -3.858 & -3.662 & -3.361 & unstable \\
\hline DLn(CEX) & $(C, 0,0)$ & -3.353 & -3.167 & -3.052 & -2.995 & stable \\
\hline Ln(CIM) & $(C, T, 2)$ & -2.209 & -3.772 & -3.549 & -3.216 & unstable \\
\hline DLn(CIM) & $(C, 0,0)$ & -3.791 & -3.341 & -3.112 & $-\mathbf{2 . 8 8 6}$ & stable \\
\hline Ln(SEX) & $(C, T, 1)$ & -2.113 & -3.882 & -3.442 & -3.129 & unstable \\
\hline DLn(SEX) & $(C, 0,0)$ & -3.891 & -3.795 & -3.544 & -3.158 & stable \\
\hline Ln(SIM) & $(C, T, 2)$ & -1.693 & -3.778 & -3.532 & -3.119 & unstable \\
\hline DLn(SIM) & $(C, 0,0)$ & -3.669 & -3.669 & -3.412 & $-\mathbf{3 . 1 0 7}$ & stable \\
\hline
\end{tabular}

\subsubsection{Cointegration test}

This paper adopts the Johansen co-integration test to test whether there is a long-term dynamic equilibrium relationship between various economic variables and industrial transformation and upgrading. Judge the number of cointegration vectors by calculating the trace statistics and the maximum eigenvalue. Table 3 and Table 4 show the specific calculation results.

From the results of the trace statistic in Table 3, under the original hypothesis that there are at most two cointegration relations, the value of the trace statistic is 30.7972 , which is greater than the critical value of $5 \%$ of significance level of 29.5806. According to the hypothesis principle, the null hypothesis can be rejected, indicating that there are at least 3 cointegration relations, and the value of $\mathrm{T}$ is 6.7805 under the condition that the null hypothesis of at most 3 cointegration relations holds, which is less than the $5 \%$ critical value of 14.3921 . The hypothesis principle can accept the null hypothesis. This shows that there are at most 3 cointegration relations.

From the results of the maximum eigenvalue in Table 4, under the original hypothesis that there are at most two cointegration relations, the maximum eigenvalue is 23.8905 , which is greater than the critical value of $5 \%$ of the significance level of 21.4571. The null hypothesis can be rejected according to the hypothesis principle. This shows that there are at least 3 cointegration relations, and under the condition that the null hypothesis of at most 3 cointegration relations is established, the maximum eigenvalue is 8.9083 , which is less than the $5 \%$ critical value of the significance level of 13.6634. According to the hypothesis principle, the original hypothesis can be accepted. This shows that there are at most 3 cointegration relations. It can be seen that the results of the two methods are consistent.

Table 3. Cointegration test results of statistics

\begin{tabular}{|c|c|c|c|c|}
\hline Null hypothesis & Eigenvalues & Trace Statistics & $5 \%$ & P Value \\
\hline None & 0.8315 & 132.4325 & 71.8746 & 0.0000 \\
\hline At most 1 & 0.6891 & 67.0209 & 52.5622 & 0.0001 \\
\hline At most 2 & 0.5563 & 30.7927 & 29.5806 & 0.0433 \\
\hline At most 3 & 0.2106 & 6.7805 & 14.3921 & 0.5451 \\
\hline At most 4 & 0.1658 & 0.0528 & 8.5233 & 0.8643 \\
\hline
\end{tabular}

Table 4. Cointegration test results of the largest eigenvalue

\begin{tabular}{|c|c|c|c|c|}
\hline Null hypothesis & Eigenvalues & Maximum Eigenvalue & $5 \%$ & P Value \\
\hline None & 0.8315 & 51.4346 & 32.7891 & 0.0000 \\
\hline At most 1 & 0.6891 & 38.2451 & 28.9078 & 0.0021 \\
\hline At most 2 & 0.5563 & 23.8905 & 21.4571 & 0.0285 \\
\hline At most 3 & 0.2106 & 8.9083 & 13.6634 & 0.6779 \\
\hline At most 4 & 0.1658 & 0.2081 & 3.8659 & 0.8541 \\
\hline
\end{tabular}

\subsubsection{Cointegration equation}

Using the special software Eviews9.0 for econometrics, the following equation can be obtained after cointegration regression using ordinary least squares method.

$\operatorname{Ln}(T S T)=1.7631+0.018775 \operatorname{Ln}(C E X)+0.000572 \operatorname{Ln}(C I M)+$
$0.007875 \operatorname{Ln}(S E X)+0.02177 \operatorname{Ln}(S M)$

The above regression equation shows that the export value of goods trade CEX and the import value of service trade SIM have passed the variable significance test at the significance level of 5\%. The regression coefficients are all positive, which is also in line with the economic significance test. This means that CEX and SIM have a positive impact on the transformation and upgrading of the industrial structure, and the impact of SIM is slightly greater than that of CEX. This shows that there is a long-term synergy between trade in goods and services and industrial transformation and upgrading. In addition, although the regression coefficients of the import value of goods trade CIM and the export value of service trade SEX are also positive, they have not passed the variable significance test at the significance level of $5 \%$. This indicates the need for further structural adjustment, optimization and upgrading of CIM and SEX. 


\section{Policy recommendations}

At present, the main task of China's industrial transformation and upgrading is to increase agricultural productivity, enhance the core competitiveness of the manufacturing industry, and vigorously develop the service industry and emerging industries. Realize the coordinated development of industry, trade, technology, labour and consumption by promoting the coordinated development of the three major industries.

\subsection{Optimize the structure of product import and export trade}

With the rapid development of the national economy, the consumption of resources has become more and more serious. China's foreign trade advantage of relying on low-cost production factors such as labour, land and environment to participate in the international division of labour and competition is no longer sustainable. It can be seen from the current Sino-US trade that independent intellectual property rights have absolute advantages and initiative in global trade competition. Therefore, it is necessary to further accelerate the cultivation of hightech products with independent intellectual property rights. Enterprises should be actively encouraged to build their own internationally renowned brands and compete for international market share by expanding exports with the help of science and technology. Moreover, it is necessary to actively expand the import of advanced technologies, key parts and components and scarce resources that are in short supply in the country, and give full play to the pulling and promoting role of import and export trade in industrial transformation and upgrading.

\subsection{Optimize the structure of service import and export trade}

In recent years, China has entered the ranks of the world's major trading countries, but the service trade has been in a state of trade deficit. This shows that the export of service trade is not significant in promoting industrial transformation and upgrading. Therefore, it is necessary to further accelerate the export of services with traditional advantages such as transportation, construction and tourism, as well as the export of new services such as electronic communications, financial insurance, information and medical services, and business logistics. It is necessary to actively strengthen a group of service outsourcing enterprises with international competitiveness. We can take advantage of the opportunity of opening to proactively undertake and contract international service projects, and fully release the pulling and promoting role of service trade in industrial transformation and upgrading.

\section{Conclusion}

All in all, foreign trade has an increasing impact on industrial transformation and upgrading. The country should continuously optimize the structure of goods and services trade, vigorously implement the "import substitution" and "export-oriented" development strategies, relying on technology-driven and market competitiveness to quantify passively as the initiative. In the international competition, we should master more internationally famous brand products with independent intellectual property rights, promote the continuous optimization of the foreign trade structure to drive the continuous transformation and upgrading of the industry, and realize the more scientific and reasonable development of the industrial economy toward high standards and high quality.

\section{References}

1. Lan Qingxin, Tian Haifeng. Empirical analysis and current research on China's trade structure changes and economic growth transition. Journal of Zhuzhou Institute of Technology, 2002, (3).

2. Li Ronglin, Jiang Qian. Analysis of the impact of import and export trade structure on industrial structure - A study based on the added value of product technology. Economics and Management Research, 2010, (4).

3. Jiang Li. Analysis of the impact of international trade on the optimization of China's industrial structure. Journal of Liaoning Normal University (Social Science Edition), 2012, (7).

4. Sun Xiaohua, Wang Yun. Does the structure of foreign trade drive the upgrading of industrial structure? Based on the semi-logarithmic model and the empirical test of structure effect. World Economic Research, 2013, (1).

5. Wen Kun. Research on the correlation between Guangdong's foreign trade structure adjustment and industrial structure upgrading. Lingnan Academic Journal, 2016, (3).

6. Jin Ling. An Empirical Study on the Relationship Between China's Export Commodity Structure Changes, Industrial Structure Optimization and Upgrading, and Economic Growth DynamicsBased on the SVAR Model. Industrial Technology Economy, 2017, (10). 